\title{
FILOLOGIA
}

\section{Tomo $3\left(195^{1}\right)$.}

R. Menéndez Pidal, "Murcia y Mortera, dos topónimos hidrográficos", pp. 1-5.-Murcia era originalmente un calificativo de agua (Aiguamurcia < aqua murcida 'agua perezosa, estancada' se opone a Aiguaviva en Tarragona). Mortera 'prado abundante en aguas' es un derivado fem. del adj. sustantivado Morta, frecuente en la toponimia del Noroeste peninsular.

D. Devoto, "Sobre paremiología musical porteña. Bailes e instrumentos en el habla bonaerense", pp. 6-83, 206.-Extensa recopilación de expresiones como "bailar en la cuerda floja", "andar en la danza", "no tener guitarra" (=guita 'dinero'), "no tener uña pa guitarrero", "dejáte de milongas", etc., con explicaciones lexicográficas e históricas muy atinadas.

A. Zamora Vicente, "Geografía del seseo gallego", pp. 84-95.-El seseo retrocede ante el influjo de la lengua oficial; coincide con las zonas de geada.

H. JANNER, "Interpretación románica de catalán", pp. 96-104--Sugiere capitale 'principal' $>{ }^{*}$ captal $>{ }^{*}$ cattal $>{ }^{*}$ catal 'importante, central' + -anus.

D. Gazdaru, "Cuatro cartas de Friedrich Diez a G. I. Ascoli", pp. 105-110.Publica y traduce al español los cuatro documentos.

E. Carilla, "Sobre [Luis José de] Tejeda y el Soneto a Santa Rosa de Lima", pp. 111-114.-Propone leer la virgen rosa (verso 10) en vez de la virgen hoja. [La corrección es desafortunada: el sentido del primer terceto sólo es claro si se mantiene la lectura original, hoja: 'pero apenas la rosa comienza a desaprisionar su hoja (=a dejar salir del botón sus pétalos), el dueño, cauteloso, se apresura a cortarla'. No tiene sentido 'la rosa desaprisiona la rosa'].

R. Moglia, "Dos nombres porteños", pp. $115^{-117}$ 7.-Se refiere a los paseos de Palermo y el Retiro. El primero proviene del nombre de Juan Domínguez Palermo, poblador del siglo xvi. El segundo, quizá "tomado de la denominación del Sitio Real homónimo de Madrid", está documentado en Buenos Aires ya en 1608 .

M. L. WAGNER, “A propósito de algunas palabras gitano-españolas”, pp. 161180.-Precisa el origen gitano y detalla las acepciones de una serie de voces: $c a$ melar 'enamorar'; camama 'burla'; jalar, jamar 'comer' (Méx. jambar, jamba'do 'glotón'); randa 'pillo'; pira 'golfo'; postin 'piel, cutis', 'lustre, brillo'; juncal 'generoso, rumboso', 'hermoso' y hollin o jollin 'pendencia, bulla'.

B. E. Vidal de BatTini, "Extensión de la $r r$ múltiple en la Argentina", pp. 181-184.-La $r r$ vibrante se encuentra en la ciudad y la provincia de Buenos Aires, en las provincias de Santa Fe (exceptuando su parte norte) y La Pampa y en los territorios de Neuquén, Río Negro y Chubut. En el resto del país domina la pronunciación asibilada, salvo en la zona que va de Neuquén hacia el 
Sur, a lo largo de la frontera con Chile y en Tierra del Fuego, donde conviven las dos variantes.

M. Goyri de Menéndez Pidal, "El Duque de Alba en el romancero de Lope de Vega", pp. 185-200.-Lope sirvió al Duque, de 1590 en adelante, por más de cuatro años, durante los cuales escribió obras que revelan su devoción por el mecenas, entre ellas algunos romances. Evidentemente son suyos los cinco siguientes: "Sobre unas tajadas rocas", "Vestido un gabán leonado", "Bajo las escasas sombras", "Mirando un corriente río" y "Albanio, un pastor de Tirse".

Y. MAlKiel, "Los derivados ibero-románicos de petrinus", pp. 201-206.-Con su función adjetiva latina sobrevive sobre todo en port.: lagar pedrinho, etc. Entre los demás derivados se encuentran el arcaísmo pédrenal $>$ pedernal; salm. pedernio; miñ. pedernão 'especie de uva' y pederneira; y esp. empédernido.

M. García Blanco, "Regacho 'lacayuelo'. Un pretendido aragonesismo en Tirso de Molina", pp. 207-211.-Es indudable que procede del ital. ragazzo, como apunta Terlingen. El paso al español bien pudo darse a través del catalán $r e-$ gatxo, forma registrada abundantemente en los diccionarios de esa lengua.

\section{Tomo $4(1952-53)$.}

G. L. Guitarte, "Amado Alonso", pp. 3-7.-Con su muerte, desaparece "la figura rectora de la filologia" en la América hispánica.

D. Gazdaru, "Cartas inéditas de Adolfo Mussafia. La Ley sintáctica ToblerMussafia y otros problemas filológicos", pp. 8-48.-Tras una interesante introducción publica y anota 17 cartas dirigidas a Ascoli entre 1869 y 1904 sobre diversos temas: formas verbales del presente neolatino, fenómenos fonéticos y morfológicos del francés, italiano, franco-provenzal y catalán antiguos, etc.

A. B. Dellepiane de Martino, "Ficción e historia en la trilogía de los Pizarros de Tirso", pp. 49-168.-Tirso escribió las tres piezas por encargo de la familia Pizarro. La primera, Todo es dar en una cosa, es una "obra mediocre" que procura ennoblecer el oscuro nacimiento de Francisco Pizarro; la segunda, Amazonas en las Indias, que es la mejor, exalta a Gonzalo Pizarro, que "murió como traidor a manos del verdugo"; y la tercera, La lealtad contra la envidia, reivindica a "la figura más discutida de la familia", Hernando Pizarro, que había estado encarcelado por más de veinte años. La autora da en su detallado estudio, al lado del argumento de las obras, las fuentes bibliográficas en que se apoyó Tirso y señala los límites entre lo histórico y lo creado por el escritor que, "como buen abogado, les da un giro distinto, mas nunca excesivo" a los hechos cuando no favorecen a los Pizarros.

D. L. Garasa, "Voces náuticas en tierra firme", pp. 169-209.-Estudio lexicográfico en orden alfabético de 35 voces de origen marinero frecuentes en $\mathrm{el}$ español americano. Entre ellas se encuentran abarrotar, ancheta, broma, caramanchel, chinchorro, estero, abenque, socar, zafacoca.-R. A. 